\title{
A Case of Pleomorphic Adenoma of the Parotid Gland with Multiple Local Recurrences through Facial to Cervical Regions
}

\author{
Masanobu Abe',2*, Yoshiyuki Mori'1, Yuki Kanno1, Kazuto Hoshi', Hideto Saijo1, \\ Takahiro Abe1, Kazumi Ohkubo', Tsuyoshi Takato' \\ ${ }^{1}$ Department of Oral \& Maxillofacial Surgery, University of Tokyo Hospital, Tokyo, Japan \\ ${ }^{2}$ Division for Health Service Promotion, University of Tokyo, Tokyo, Japan \\ Email: abem-ora@h.u-tokyo.ac.jp
}

Received 28 June 2014; revised 15 August 2014; accepted 28 August 2014

Copyright (C) 2014 by authors and Scientific Research Publishing Inc.

This work is licensed under the Creative Commons Attribution International License (CC BY).

http://creativecommons.org/licenses/by/4.0/

(c) (i) Open Access

\begin{abstract}
Pleomorphic adenoma is the most common benign parotid gland tumor. Although its local recurrence rate is known to be high, the recurrence extending to the cervical region is rare. Here we report a case of a young female (25 years old) with pleomorphic adenoma of the parotid gland which showed multiple recurrences through facial to cervical regions over a span of eight years. We also discuss how this benign tumor with a high recurrence rate has been treated in other cases, and how it should be treated.
\end{abstract}

Keywords

Pleomorphic Adenoma, Parotid Gland, Salivary Neoplasm

\section{Introduction}

The most common salivary gland neoplasm, pleomorphic adenoma, is most frequently found in the parotid gland in middle-aged women. It is known as a benign tumor with slow progression, and malignant transformation is rare. Pleomorphic adenoma has a high rate of local recurrence (1\% - 45\%) [1]-[3] and the management of recurrent tumors is challenging because the probability of subsequent recurrence increases with each recurrent episode, making local control increasingly difficult and making damage to the facial nerves more likely [4].

\footnotetext{
${ }^{*}$ Corresponding author.
}

How to cite this paper: Abe, M., et al. (2014) A Case of Pleomorphic Adenoma of the Parotid Gland with Multiple Local Recurrences through Facial to Cervical Regions. Open Journal of Stomatology, 4, 441-445. 
We treated a young woman with pleomorphic adenoma of the parotid gland who showed multiple recurrences through the facial region to the cervical region. Tumor recurrence extending to the cervical region is reported to be rare in pleomorphic adenoma [4]. Here we present the case report and discuss how this benign tumor with a high recurrence rate should be treated. The operation, the management of the facial nerve, the role of postoperative radiotherapy, etc., are focused on.

\section{Case Report}

A 25-year-old female was referred to our department (Oral and Maxillofacial Surgery) in March 2000. She complained of soft tissue swelling and pain on the right side of the subauricular region that had disappeared and relapsed several times over the prior year. On physical examination, this mass was well defined and showed hard elasticity and abundant mobility by palpation. The MRI showed a sharply emarginated round mass in the right superficial parotid gland. The mass was high intensity on T2-weighted images. The size of the mass was $30 \times$ $25 \mathrm{~mm}$ (Figure 1). As the clinical differential diagnosis of this mass, pleomorphic adenoma, warthin tumor, and neurogenic tumor, such as trigerminal shwannoma, were considered.

A surgical procedure was performed under general anesthesia in May 2000. After a modified Blair's incision (S-shaped preauricular and submandibular incision), the mass was exposed and removed along with the surrounding tissue of the membrane by a conservative surgical procedure called extracapsular enucleation. A pathologic evaluation of the resected mass identified the tumor as a pleomorphic adenoma (myxoid subtype) of the right parotid gland. Mostly, light eosinophilic, ovate or short spindle-shaped cells with mucinous matrix were scattered. Partially, adepithelial cells were observed in a paving stone arrangement. No malignancy was identified in the specimen.

Although the patient presented temporary facial nerve palsy after the surgery, the dysfunction was resolved within three months. Vitamin B12 was administered after the surgery. In January 2003, the patient presented with multiple lesions around the right angle of the mandible. The difference between true tumors and lymph nodes was difficult to decipher, and a follow-up of this issue was conducted.

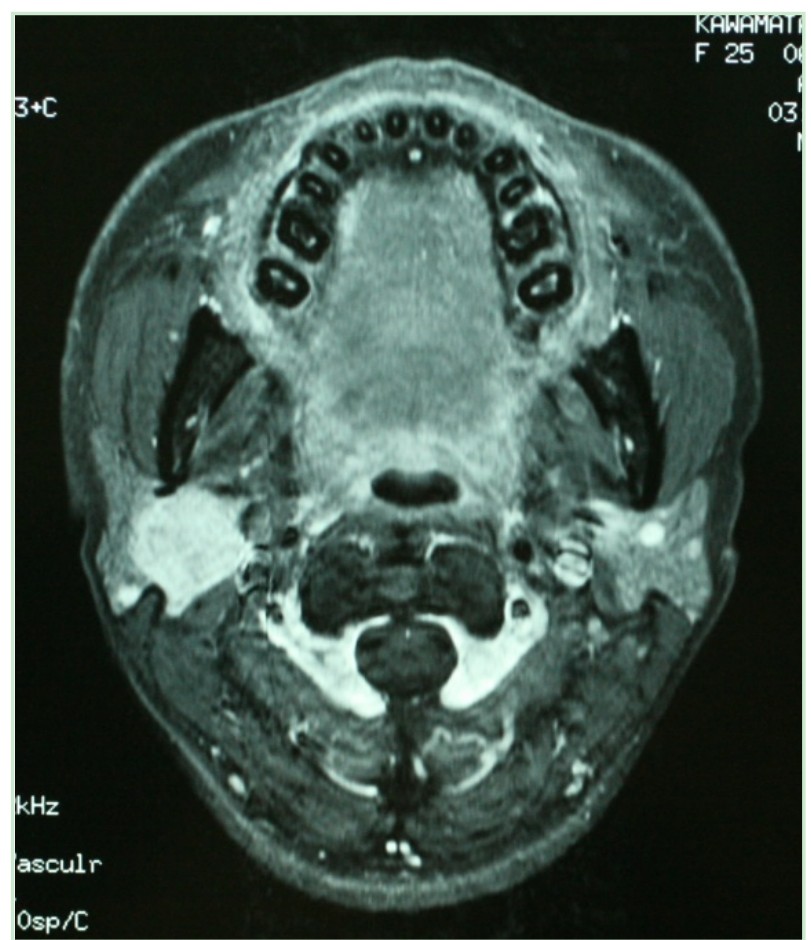

Figure 1. Preoperative MRI of the patient. The MRI showed a sharply emarginated round mass in the right superficial parotid gland. The mass was of high intensity on T2-weighted images. The size of the mass was $30 \times 25 \mathrm{~mm}$. 
In December 2005, the patient presented with an enlarged mass: an MRI showed a multinodular mass of high intensity on T2-weighted images from the deep lobe into the superficial lobe of the right parotid gland (Figure 2). The maximum dimension of the lesion was its 22-mm dia. A surgical procedure was performed for the mass under general anesthesia in June 2006. An s-shaped preauricular incision and a submandibular extension were used to gain access to the mass. The facial nerve and all of its branches were identified with the aid of a nerve monitor. A possibly recurrent mass in the superficial lobe of the parotid gland was identified, and a nodule was dissected for an intraoperative pathology consultation. The specimen revealed a recurrent pleomorphic adenoma without malignant transformation. Therefore, partial parotidectomy of the superficial and deep lobes was performed with an elective neck dissection. A pathological evaluation identified the mass as a recurrent pleomorphic adenoma of the right parotid gland. No malignant transformation was identified in the specimens. A neck dissection specimen was comprised of three free-of-disease lymph nodes.

In May 2008, several lesions which were suspected recurrent pleomorphic adenomas were found through the face to the cervical region by an MRI. The largest lesion had a diameter of $6 \mathrm{~mm}$. In October 2008, five of the lesions were identified and removed under general anesthesia (Figure 3). A pathological evaluation identified the lesions as recurrent pleomorphic adenomas in the right facial and cervical regions. Malignant transformation was not identified in the specimens. In April 2009, an MRI showed a multinodular mass in the neck. Recurrent lesions were removed in April 2010 and in December 2011 respectively under local anesthesia. Although the patient presented temporary facial nerve palsy after the surgery in 2011, the dysfunction was healed within a day.

\section{Discussion}

We have experienced a rare case of recurrent pleomorphic adenoma that extends to the cervical region. Papadogeorgakis et al. recently reported the case of a 38-year-old female who showed multinodular recurrence of a parotid gland pleomorphic adenoma in the cervical region. Multiple painless, well-defined, palpable and nontender masses and subcutaneous nodules of the right parotid and homolateral cervical region were revealed by

clinical examination [4].

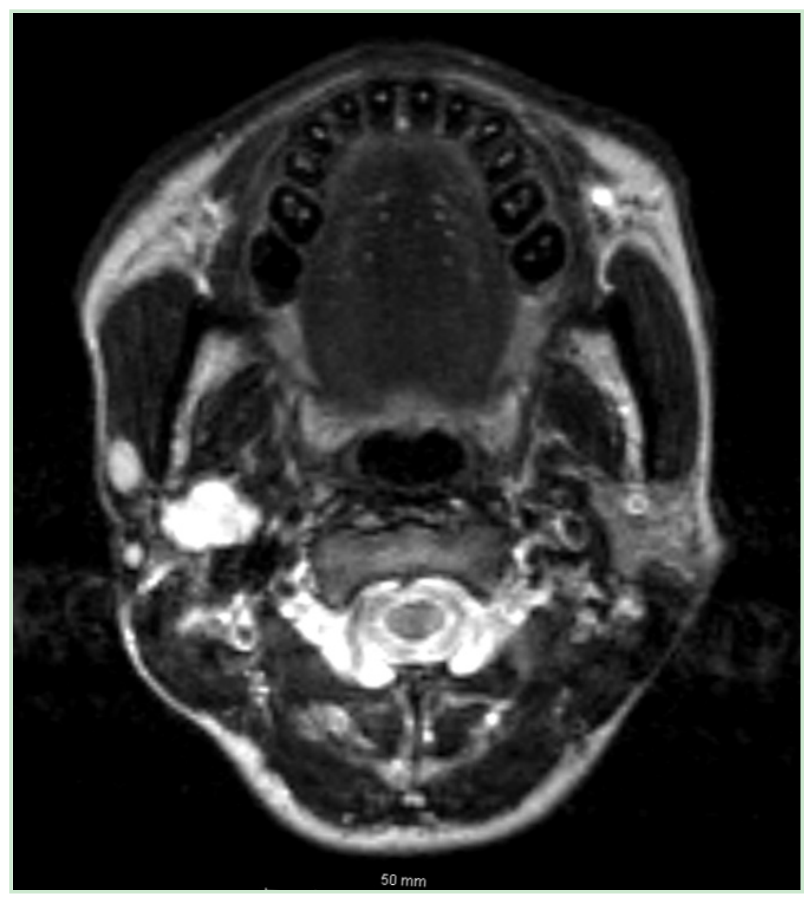

Figure 2. Preoperative MRI of the recurrent tumor (six years after the primary operation). The MRI showed a multinodular mass of high intensity on T2-weighted images from the deep lobe into the superficial lobe of the right parotid gland. The maximum dimension of the lesion was its $22 \mathrm{~mm}$ dia. 


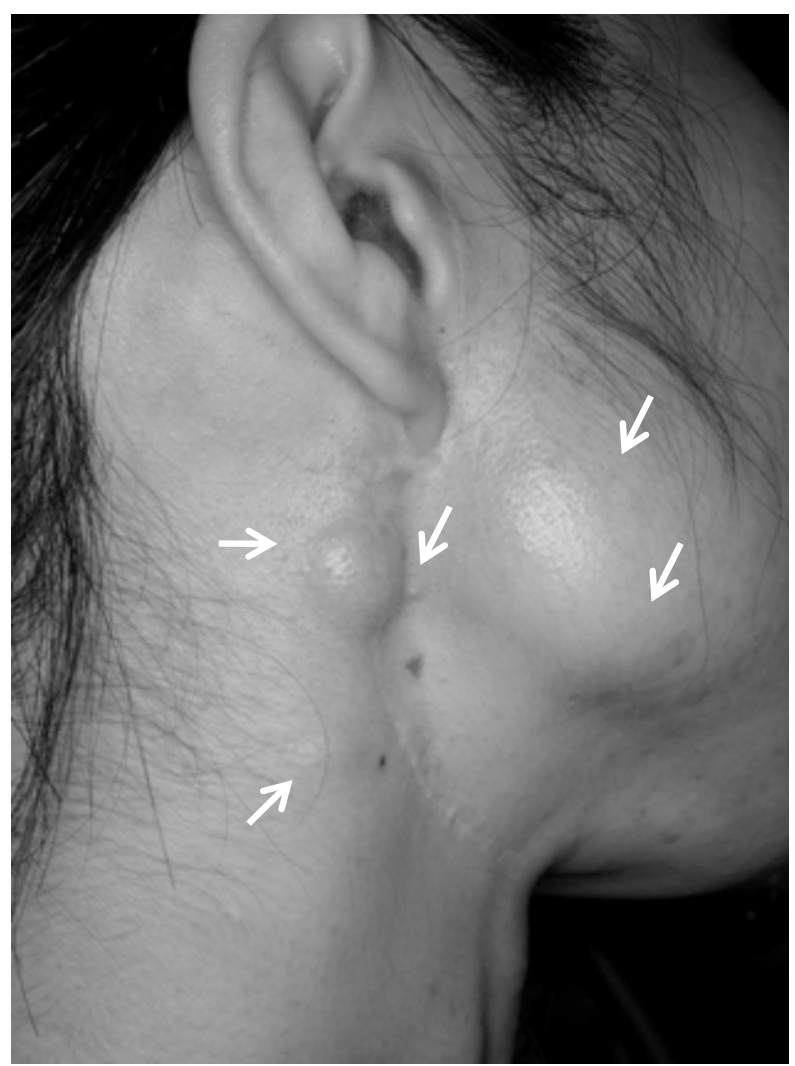

Figure 3. Preoperative clinical photograph of the recurrent tumor. Preoperative clinical photograph of the recurrent tumor (indicated by arrowheads) and its extension to the neck (eight years after the primary operation). Five of the lesions were identified as recurrent pleomorphic adenomas in the right facial and cervical regions.

The standard treatment of pleomorphic adenomas in the parotid gland is a surgical procedure. However, adverse outcomes of the surgical procedures are common. As noted in the Introduction, the recurrence rate of pleomorphic adenoma after surgery has been reported to be $1 \%-45 \%$ [1]. The wide range of the rate depends on the type of surgical procedures. The recurrence rate after tumor enucleation has been reported to be $20 \%$ to $45 \%$ [1]. The high rate of recurrence is considered to be associated with positive margins consisting of incomplete tumor capsules. Other suggested causes of pleomorphic adenoma recurrence are the perforating pseudopodia of the tumor, capsule rupture by the surgical procedure, and the proximity of the tumor to facial nerves [2]. In this case, although tumor was removed along with the surrounding tissue of the membrane in the primary surgical procedure, the size of tumor was not small, therefore capsule rupture might have occurred in this procedure and have led the tumor recurrences. More comprehensive dissection methods, extracapsular dissection or superficial parotidectomy are considered more effective to prevent tumor recurrence compared to enucleation when a pleomorphic adenoma is limited to the superficial lobe of the parotid gland. After extracapsular dissection or superficial parotidectomy, recurrence rates are reduced to less than 5\% [1].

The most serious issue concerning surgical procedure of pleomorphic adenoma is a high rate of facial nerve dysfunction. The rates of transient facial nerve dysfunctions are reported to be $11 \%-60 \%$ [1]. The wide range of the rate depends on the type of surgical procedures and the rate is much higher when total parotidectomy is selected (60\%) [1]. The rate is much lower when enucleation, extracapsular dissection, or superficial parotidectomy is selected; the rates of transient facial nerve dysfunctions are $11 \%, 11 \%$, and $26 \%$, respectively [1].

Recurrent pleomorphic adenomas should be treated with re-resection principally, but the risks of facial nerve dysfunction, Frey syndrome, salivary fistula, and necroses increase with each operation. Several authors also suggested that postoperative radiation therapy (XRT) is effective for recurrent pleomorphic adenomas and cases 
with positive margins after resection [5]-[7]. Liu et al. conducted a retrospective review of pleomorphic adenoma patients who received XRT, and they recommended that XRT should be given to patients in whom there is tumor spillage, residual disease, or recurrences [6]. In Japan, XRT for pleomorphic adenoma, a benign tumor, has been considered an excessive medical therapy. However, taking the good clinical outcomes after XRT into account, XRT could be effective against a pleomorphic adenoma with multiple recurrences. Depending on factors such as the rapidity of recurrence, the patient's age, and completeness of resection, XRT may be a useful therapy for pleomorphic adenomas.

It is proposed that the recurrence rates of pleomorphic adenomas might depend on the selection of the type of operation procedure. However, the adverse outcomes like facial nerve dysfunction are serious problems by the excess dissections of tissues, especially, for young patients like this case. Therefore we have to take the social background of each patient into consideration and make adequate judgments for each treatment.

\section{References}

[1] Witt, R.L. (2002) The Significance of the Margin in Parotid Surgery for Pleomorphic Adenoma. Laryngoscope, 112, 2141-2154. http://dx.doi.org/10.1097/00005537-200212000-00004

[2] Lam, K.H., Wei, W.I., Ho, H.C. and Ho, C.M. (1990) Whole Organ Sectioning of Mixed Parotid Tumors. The American Journal of Surgery, 160, 377-381. http://dx.doi.org/10.1016/S0002-9610(05)80547-1

[3] Witt, R.L. and Rejto, L. (2009) Pleomorphic Adenoma: Extracapsular Dissection versus Partial Superficial Parotidectomy with Facial Nerve Dissection. Delaware Medical Journal, 81, 119-125.

[4] Papadogeorgakis, N., Kalfarentzos, E.F., Petsinis, V., Parara, E. and Kopaka, M.E. (2012) Multinodular Neck Recurrence of Parotid Gland Pleomorphic Adenoma: A Case Report. Journal of Oral and Maxillofacial Surgery, 16, 137-140. http://dx.doi.org/10.1007/s10006-011-0279-4

[5] Mendenhall, W.M., Mendenhall, C.M., Werning, J.W., Malyapa, R.S. and Mendenhall, N.P. (2008) Salivary Gland Pleomorphic Adenoma. American Journal of Clinical Oncology, 31, 95-99. http://dx.doi.org/10.1097/COC.0b013e3181595ae0

[6] Liu, F.F., Rotstein, L., Davison, A.J., Pintilie, M., O’sullivan, B., Payne, D.G., Warde, P. and Cummings, B. (1995) Benign Parotid Adenomas: A Review of the Princess Margaret Hospital Experience. Head Neck, 17, 177-183. http://dx.doi.org/10.1002/hed.2880170302

[7] Chen, A.M., Garcia, J., Bucci, M.K., Quivey, J.M. and Eisele, D.W. (2006) Recurrent Pleomorphic Adenoma of the Parotid Gland: Long-Term Outcome of Patients Treated with Radiation Therapy. International Journal of Radiation Oncology*Biology*Physics, 66, 1031-1035. http://dx.doi.org/10.1016/j.ijrobp.2006.06.036 
Scientific Research Publishing (SCIRP) is one of the largest Open Access journal publishers. It is currently publishing more than 200 open access, online, peer-reviewed journals covering a wide range of academic disciplines. SCIRP serves the worldwide academic communities and contributes to the progress and application of science with its publication.

Other selected journals from SCIRP are listed as below. Submit your manuscript to us via either submit@scirp.org or Online Submission Portal.
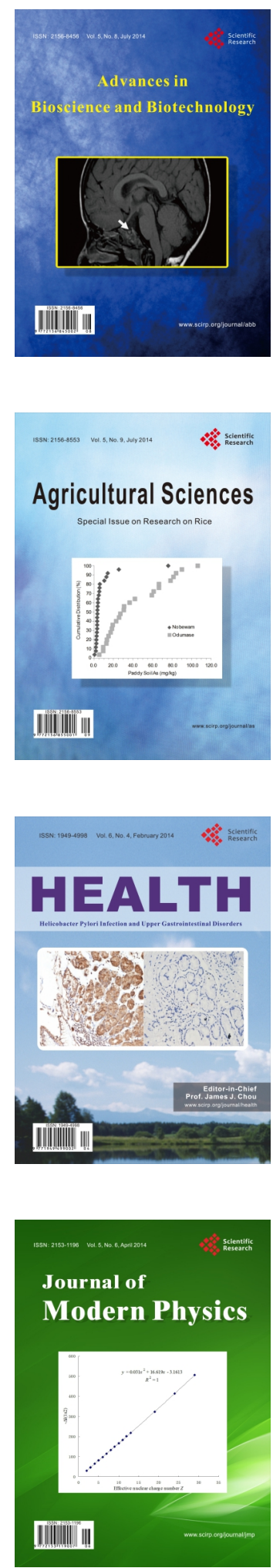
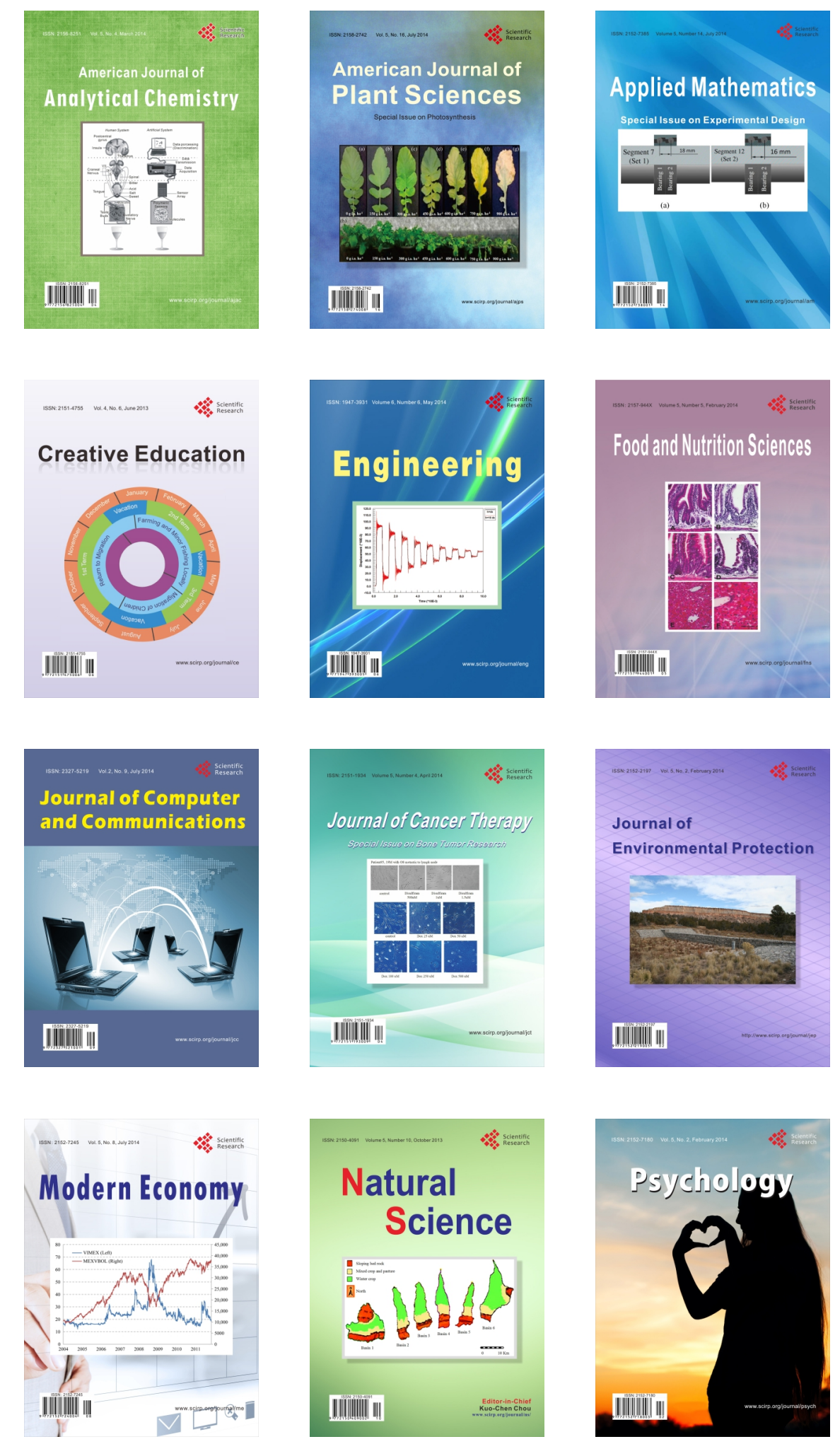